\title{
Surveying the best in translation
}

\author{
Matthew Grunseth, Calvin Chen, Ryan Kelly, Sangeeta Bardhan Cook, George Megaw \& Larry Couture
}

How to build powerful translational research centers.

T

ranslational research is conducted primarily

to advance the development of specific applications for a technology or scientific discovery. This often includes but is not limited to proof-of-concept studies, efficacy studies and preclinical investigational new drug application-enabling studies, all of which are submitted to the US Food and Drug Administration (FDA). Also, translational research often requires access to specialized resources such as good manufacturing practice (GMP) facilities, high-throughput screening technologies and large-animal laboratories. Over the past decade, an increasing number of academic institutions have attempted to build or access these types of resources, but what are the key components of efficient translational research, and how might an institution improve its offerings?

\section{What's out there?}

Commercializing translational research is expensive, but that expense can be offset by the ways it can help scientists weather funding droughts. A well-equipped infrastructure with the right resources can act as a grant multiplier, maximizing the allocation and expenditure of grant dollars. For example, institutionally managed, and often subsidized, resources made available to grant-funded researchers typically cost a fraction of what external, for-profit providers charge for the same resource. Thus, in theory, a grant awarded to an investigator at a

\footnotetext{
Matthew Grunseth is Senior Manager, Calvin Chen is Manager, Ryan Kelly is Senior Manager, Sangeeta Bardhan Cook is Manager, George Megaw is Director and Larry Couture is Senior Vice President of the Center for Applied Technology Development, Beckman Research Institute at City of Hope, Duarte, California, USA. e-mail:mgrunseth@coh.org,calchen@coh.org, rykelly@coh.org,scook@coh.org, gmegaw@coh.orgorlcouture@coh.org.
}

properly resourced translational research institution could produce results on par with, or greater than, those derived from larger awards given to investigators at institutions lacking these capabilities.

The proper translational infrastructure can also help build stronger intellectual property portfolios around new technologies and allow first movers to be amply rewarded, thereby increasing the likelihood of executing a license agreement with industry or attracting seed investors for a startup. The goal, then, is for institutions with adequate resources and infrastructure to allow projects to succeed or fail based on scientific merits and not on the amount of short-term gap funding available through challenge grants, California Institute of Regenerative Medicine awards or popular charities.

At City of Hope (Box 1), located in Duarte, California, we were helped in the development of our own translational capabilities by the founding of the institution's Center for Applied Technology Development in 1998, which handles biologics and cell therapeutics, and the institution's Developmental Therapeutics Program in 2007, which handles small molecule therapeutics. Both were established through directed philanthropy. Similarly, the Knight Cancer Institute at the Oregon Health and Science University raised large lump sum endowments to kick-start their efforts (http://www.ohsu.edu/xd/about/news_events/ news/2013/09-21-nike-co-founder-issues-b. (fm), and other institutions have received funding via the Clinical and Translational Science Award (CTSA) program to establish a translational center within their respective organizations.

In order to offer the best advice on developing an efficient translational institution, we wanted to gauge the current landscape. We conducted a survey to identify the critical components of successful translationally focused research institutions, targeting centers previously identified as having some degree of a translational missionnotably the National Cancer Institute's National Comprehensive Cancer Network centers and the US National Institutes of Health's CTSA centers. (The National Cancer Institute designates the Comprehensive Cancer Center title to institutions that exhibit capabilities that bridge laboratory-, clinicaland population-based research. The US National Institutes of Health's CTSA program honors collaborative translational and clinical research among research organizations that have complementary offerings.) Of the 41 Comprehensive Cancer Centers and 61 CTSA designations we reached out to, we received 20 responses (Supplementary Table 1) on infrastructure, expertise and personnel.

Our study showed that all had smallanimal facilities as well as intellectual property and licensing personnel on site. Most had large-animal facilities (80\%) and designated regulatory affairs staff $(75 \%)$. Fewer than half had nonhuman primate facilities, but all had at least one type of GMP facility on site. Importantly, just $40 \%$ of responding institutions had an annual research budget in excess of $\$ 500$ million, meaning that improvements in infrastructure might not be as expensive as you think. (Full data can be found in Supplementary Table 1.)

\section{Recommendations}

Based on our experience and the survey, we can offer recommendations for the requirements of an efficient, translationally focused, sustainable institution, one capable of advancing technology from the bench to the marketplace. First, you will need multiple funding sources (such as fee-for-service contracts, endowments and royalty streams) in addition to traditional grant funding. Such alternative revenue streams help develop backstops against grant funding droughts and enable uninterrupted development of emerging technologies. Second, if 


\section{Box 1 City of Hope}

City of Hope $(\mathrm{COH})$ is a nonprofit clinical research center in Duarte, California. A nationally ranked top 15 cancer hospital, $\mathrm{COH}$ is perhaps best known for its work in oncology therapy and research. $\mathrm{COH}$ was a founding member of the National Cancer Institute's National Comprehensive Cancer Network. Additionally, $\mathrm{COH}$ is a world leader in hematopoietic stem cell transplants and has performed over 11,000 as of 2012 (http:// www.cityofhope.org/hct).

In 1977, COH researchers Arthur Riggs and Keiichi Itakura worked with the thenstartup company Genentech to produce the first human protein in Escherichia coli. $\mathrm{COH}$ also played a leading role in the development of synthetic human insulin in 1978 and has enjoyed successes in the fields of gene therapy and stem cell-based regenerative medicine.

your translational resources, such as GMP facilities and good laboratory practice (GLP) laboratories, are not operating at $100 \%$ capacity, and the number of internal projects is limited, these resources could be made available to third parties for contract work; the rise of virtual startups means there is no shortage of biotech companies looking for affordable, highquality services.

In general, a complete translational research institution should address three core areas (Table 1): preclinical development, clinical development, and business development and licensing. Institutions, depending on how many of these core areas they have, can then be categorized into three levels (Table 2).

Level 1. To be considered a translationally focused research institution, you must have these minimal capabilities. First, an institution must be able to manufacture lead compounds (small molecules or biologics). This work can be done via outsourcing, of course, but contract manufacturing services for GMP products for preclinical toxicology and/or pharmacokinetic studies and phase 1 trials are often cost prohibitive. In-house facilities not only keep costs under control but also can be more immediately available as a resource to researchers. In addition, in-house facilities can be more flexible in terms of process and are often easier for researchers to approach and successfully engage than third-party commercial contract manufacturing organizations.

Second, a Level 1 institution must be capable of performing small-animal studies (basically, rodents) on site; this provides an important efficacy checkpoint and a means of showing proof of concept before additional resources and funding are expended. Proof-of-concept studies conducted in vivo are required at a minimum to engage a serious industry partner or investor and are also needed to justify a potential clinical trial to the FDA and show definitive efficacy.

Third, in-house regulatory affairs personnel should be available to draft and file IND applications and manage the critical and often burdensome communications with the FDA. A competent in-house regulatory affairs team can effectively guide researchers through the FDA process while keeping all of the technology's stakeholders (inventors, institutional leadership and philanthropic givers) informed. In our survey, $75 \%$ of the institutions polled had integrated regulatory staff into their translational infrastructure as a core resource. Engaging the regulatory team early in the development of a lead molecule ensures everything is done with a view toward satisfying FDA requirements.
Even a basic translational institution must be capable of advancing lead candidates into the clinic. Relying on external, for-profit partners with less 'skin in the game' to lead a first-in-human study is often fraught with excessive delays that are compounded by clinical trials being the most expensive and arduous of all components of translation. The start-up cost is largely dependent on the resources and personnel already available to an institution: a hospital site, doctors, nurses, institutional review board specialists, clinical coordinators, medical equipment and existing subject recruitment are all parts of conducting clinical trials. However, once the facilities are put into place they easily reduce costs and can also provide incoming revenue as a leasable resource.

Adding phase 1 capabilities carries the highest barrier to entry, and it may be a nonstarter for smaller and traditionally basic researchfocused institutions to build a research hospital. If this is the case, the institution can identify partners for this work, perhaps universities with medical schools or regional research hospitals that have the ability to recruit populations for trials and also have institutional review board specialists and coordinators to continually run the trials.

The final basic necessity for a Level 1 translational institution is full-time intellectual property and contracts personnel on site. This function is usually performed by the office of technology transfer or technology licensing. These personnel prosecute patents that protect discoveries and help attract commercial partners who require market exclusivity. Revenue derived from any license can defer the costs associated with translational infrastructure and help move an institution toward a sustainable model.

If all of these elements are in place, you should be able to advance discoveries through phase 1 completely in house. Properly designed phase 1 studies can provide data that shed light

Table 1 Translational infrastructure by category.

\begin{tabular}{ll} 
Preclinical development & Clinical development resources \\
\hline High-throughput screening capabilities & $\begin{array}{l}\text { On-campus good laboratory practice and good } \\
\text { manufacturing practice facilities }\end{array}$ \\
\hline In silico and/or bioinformatics modeling capabilities & $\begin{array}{l}\text { Quality assurance and quality control expert } \\
\text { teams }\end{array}$ \\
\hline Structure-activity relationship research group & $\begin{array}{l}\text { Regulatory affairs personnel to prepare and } \\
\text { advance investigational new drug applications }\end{array}$ \\
\hline In vitro validation capabilities & $\begin{array}{l}\text { Hospital facilities and patient base to support } \\
\text { clinical trials }\end{array}$ \\
\hline Toxicology and early stage pharmacokinetic capabilities & Broad clinical expertise
\end{tabular}

Small-animal, large-animal and nonhuman primate facilities

Business development and licensing

Intellectual property and licensing personnel

Contract negotiation team

Continuity of basic researchers, clinicians, regulatory affairs personnel, and good laboratory practice and good manufacturing practice facilities

Connections to other academic technology transfer offices and/or academic institutions

Connections to big pharma, biotech, startups and incubators

Access to gap funding 
Table 2 Tiers of translation. There are three levels of translation centers, based on capabilities.

\begin{tabular}{l} 
Level 1 \\
\hline Good manufacturing practice (GMP) facility on site \\
Clinical trial capabilities on site \\
Regulatory affairs personnel on site \\
Small-animal facility on site \\
Pharmacokinetic and/or pharmacodynamic expertise \\
Intellectual property and contracts personnel on site \\
Quality assurance personnel on site
\end{tabular}

Level 2

Project management personnel on site

Small molecule lead-optimization capabilities on site

Internal gap funding
Level 3

Business development personnel to support GMP facilities

Multiple types of GMP facilities

Large-animal and nonhuman primate facilities on early efficacy in addition to the requisite safety endpoints, and these early data may derisk the technology enough to garner interest from industry or licensing partners; these data also can provide a value inflection point for the asset.

It is not practical for a Level 1, not-for-profit research institution to submit an IND application for entrance into a phase 2 study for a lead molecule to the FDA for approval because of the exponential rise in costs moving beyond phase 1 . Rather, the goal for these institutions should be to advance select technologies or molecules enough that a commercial partner would be comfortable stepping in and shepherding the technology the rest of the way.

Level 2. This middle level should be the goal of all institutions, despite budget size, as it can be reached from Level 1 with modest investments. Our experience suggests that effective Level 2 centers are more proficient in moving projects forward than Level 1 institutions, due at least in part to three additional capabilities: project management personnel, centralized lead-optimization facilities and gap-funding programs.

Project management. A project manager can serve several functions, including keeping researchers focused, directing researchers toward projects more suitable for translational research and coordinating multidisciplinary groups (manufacturing, technology transfer, regulatory affairs, animal facilities, etc.) to ensure the project is moving forward smoothly. Interestingly, despite pharmaceutical project management personnel having a median salary of $\$ 110,000$ per year ${ }^{1}$, only $40 \%$ of our polled institutions employ them. This is especially surprising considering that $40 \%$ of institutions have small-animal, largeanimal and nonhuman primate facilities on site-the budget for the primate facility alone can easily run into multiple millions of dollars on an annual basis ${ }^{2}$. For example, aside from the costs associated with the buildings and facilities, the average cost for maintaining a primate on an annual basis can be as high as $\$ 60 /$ day. If the institution has
500 primates then this equates to an annual cost of nearly $\$ 11$ million per year.

Therefore, the decision to have project management capabilities does not appear to be overly influenced by the size of the institution's research budget. Of the institutions polled in our survey, $25 \%$ with project management capability have budgets between $\$ 50$ million and $\$ 100$ million, $25 \%$ have budgets between $\$ 250$ million and $\$ 500$ million and the remaining $50 \%$ have budgets exceeding $\$ 500$ million.

Centralized, on-site lead-optimization facility. Optimizing a lead compound gives the drug the best chance of success. Thus, in-house lead-optimization experts and facilities allow researchers to focus on research rather than spending time identifying and negotiating with third parties over contracts. As big pharma continues to shed research personnel and shift their focus away from discovery and lead optimization, these experts are becoming available for recruitment to your research institution.

Gap funding. Research budgets have continued to diminish because of a lack of available grant funding, such as the $\$ 1.71$ billion budget cut for the US National Institutes of Health after sequestration ${ }^{3}$. This means that institutions need funds to bridge gaps for their select translational projects. Operating an internal gap fund equivalent to $1 \%$ of an institution's research budget is a reasonable goal for smaller institutions. For larger institutions ( $\$ 500$ million to $\$ 1$ billion in annual research funding), a gap fund of about $0.25-0.5 \%$ of the annual research budget should be sufficient. The gap fund may be allocated from the institution's endowment or gifts and supplemented with funds from indirect charges on corporate-funded research projects, fee-for-service projects and licensing-derived income. The size of this fund will depend largely on how many projects an institution wishes to fund annually. To have any meaningful impact, we recommend this fund allots a minimum of $\$ 1$ million per project chosen for development. The main cost driver for being a Level 2 institution is this internal gap funding.

A gap fund can support in vitro and in vivo proof-of-concept studies, allowing go or no-go project decisions to be based on scientific data and not on funding. The projects or proposals for gap funding should be reviewed and selected by an independent committee comprising internal and external participants with relevant industry and technical experience. For example, City of Hope has a committee that meets bi-annually to review program proposals for gap funding. Internal members of the committee include research professors, medical staff, key institutional administrators and executives. External members include venture capitalists, serial entrepreneurs, pharmaceutical and biotech veterans, and commercialization consultants. In City of Hope's case, this committee-balanced with technical and business expertise-holds the authority necessary to determine which projects will or will not receive gap funding.

Level 3. Unsurprisingly, the capabilities of a superb institution are the most expensive to develop and are difficult to attain unless you have an annual budget in excess of $\$ 250$ million. These capabilities include a robust business development team, multiple GMP facilities and large-animal and/or nonhuman primate facilities. The business development personnel fill the project queue for the GMP facilities with external clients whenever possible, and the higher fees paid by these clients help offset the overhead costs associated with managing the facility. Operating multiple GMP facilities also allows you to have translational capabilities in more than a single field. However, the cost to invest in more than one GMP facility may often be prohibitively expensive, as only $25 \%$ of institutions surveyed maintain multiple facilities, and $75 \%$ of those institutions have annual research budgets in excess of $\$ 250$ million.

In addition, although nonhuman primate studies are not always necessary for entrance into the clinic, they are often a requirement set forth by the FDA for IND submissions. Specifically, most vaccine- and biologicsfocused technologies use mice and canine models, which may extrapolate poorly onto human clinical outcomes. Thus, if your institution focuses on biologics or vaccines, then a primate facility should be strongly considered. 


\section{Conclusions}

Based on our poll, the data suggest that only larger research institutions can bring to bear all the resources required to excel in translational research: just $15 \%$ of respondents in our survey possess all facets of a Level 3 translational research institution-small- and large-animal facilities, more than one type of GMP facility, regulatory affairs personnel, licensing personnel, project management personnel, human clinical trial capabilities and lead optimization on site. Each of these Level 3 institutions has an annual research budget of more than $\$ 500$ million.

The most telling finding of the 20instutition survey is how consistently absent project management personnel are across all types of institutions regardless of funding or range of facilities. Incidentally, this aspect is the least expensive capability to develop. In our experience, empowered project managers can have an immediate impact in facilitating the transit of preclinical work to patients in need.

The good news is that smaller institutions (annual research budgets of less than \$249 million) can also find success by investing in a lead-optimization facility, a small-animal facility, a small molecule or biologics GMP facility (made available to third parties on a fee-for-service basis), clinical trial facilities, business development and/ or intellectual property personnel, regulatory personnel and/or project management personnel. These additions will move an institution to Level 2, but if setting up this type of infrastructure in-house is still out of your reach because of budget considerations, you could set up formal collaborations with other regional institutions, thus allowing access to those assets.

Only $25 \%$ of the institutions surveyed possess all of the Level 2 resources, but this is not because of budget limitations. Thus, by hiring project managers and regulatory affairs personnel and by employing licensing personnel, it is possible to grow from a Level 1 to a Level 2 and eventually a Level 3 institution that is sustainable and successful in translating research toward the clinic and beyond.

Note: Supplementary information is available in the online version of the paper (doi:10.1038/nbt.2887).

\section{ACKNOWLEDGMENTS}

The authors would like to thank S. Kwan for her support and R. Sukumar for his assistance in preparing the manuscript for publication.

\section{COMPETING FINANCIAL INTERESTS}

The authors declare no competing financial interests.

1. Levinson, M. Inside project managers' paychecks: PM salary survey results. $\mathrm{ClO}$ (22 April 2010).

2. Anonymous. Harvard Medical School to close primateresearch center. Harvard Magazine (23 April 2013).

3. Kaiser, J. NIH details impact of 2013 sequester cuts. Sciencelnsider (8 May 2013). 